\title{
Barriers to bowel scope (flexible sigmoidoscopy) screening: a comparison of non-responders, active decliners and non- attenders
}

Christian von Wagner ${ }^{1 *}$ D, Bernardette Bonello ${ }^{1,2}$, Sandro Stoffel ${ }^{1}$, Hanna Skrobanski ${ }^{1,3}$, Madeleine Freeman ${ }^{1}$, Robert S Kerrison ${ }^{1}$ and Lesley M McGregor ${ }^{1}$

\begin{abstract}
Background: Participation in bowel scope screening (BSS) is low (43\%), limiting its potential to reduce colorectal cancer (CRC) incidence and mortality. This study aimed to quantify the prevalence of barriers to BSS and examine the extent to which these barriers differed according to non-participant profiles: non-responders to the BSS invitation, active decliners of the invitation, and non-attenders of confirmed appointments.
\end{abstract}

Methods: Individuals invited for BSS between March 2013 and December 2015, across 28 General Practices in England, were sent a questionnaire. Questions measured initial interest in BSS, engagement with the information booklet, BSS participation, and, where applicable, reasons for BSS non-attendance. Chi-square tests of independence were performed to examine the relationship between barriers, non-participant groups and socio-demographic variables.

Results: 1478 (45.8\%) questionnaires were returned for analysis: 1230 (83.2\%) attended screening, 114 (7.7\%) were nonresponders to the BSS invitation, 100 (6.8\%) were active decliners, and 34 (2.3\%) were non-attenders. Non-responders were less likely to have read the whole information booklet than active decliners $\left(x^{2}(2, N=157)=7.00, p=0.008\right)$ and non-attenders $\left(x^{2}(2, N=101)=8.07, p=0.005\right)$. Non-responders also had lower initial interest in having BSS than either active decliners $\left(x^{2}(2, N=213)=6.07, p=0.014\right)$ or non-attenders $\left(x^{2}(2, N=146)=32.93, p<0.001\right)$. Overall, anticipated pain (33\%) and embarrassment (30\%) were the most commonly cited barriers to BSS participation. For non-attenders, however, practical, appointment-related reasons were most common (27\%).

Conclusions: Interventions to improve BSS uptake should be more nuanced and use targeted strategies to address the specific needs of each group.

Keywords: Bowel scope, Screening, Colorectal cancer, Flexible sigmoidoscopy, Non-attendance

\section{Background}

Colorectal cancer (CRC) is the second most common cause of cancer-related deaths in the UK [1], making prevention and early diagnosis a priority in cancer control. Results from the UK Flexible Sigmoidoscopy (FS) Trial showed that a single FS examination with removal of pre-malignant growths reduced CRC mortality by $43 \%$ and CRC incidence by a third [2]. In

\footnotetext{
*Correspondence: c.wagner@ucl.ac.uk

'Research Department of Behavioural Science and Health, University College London, Gower Street, London WC1E 6BT, UK

Full list of author information is available at the end of the article
}

response to these results, and other worldwide research supporting FS as a screening modality [3, 4], NHS England now offer men and women a single, free FS screen at age 55 as part of the NHS Bowel Cancer Screening Programme. This is known as 'bowel scope screening' (BSS) and was introduced in March 2013. A recent follow-up of the UK trial has shown that the benefits of a FS screen are retained 17 years after the initial examination [5], providing further evidence as to the need to increase uptake of the test. Uptake among the screening-eligible population will be key to

(c) The Author(s). 2018 Open Access This article is distributed under the terms of the Creative Commons Attribution 4.0 International License (http://creativecommons.org/licenses/by/4.0/), which permits unrestricted use, distribution, and 
realizing the projected public health benefits of this screening test [6].

A recent study analysing BSS invitations sent within the first 14 months of BSS roll out in England (21,187 invitations) found that only $43 \%$ of those invited attended their pre-booked appointment [7]. Furthermore, people from more socioeconomically deprived and ethnically diverse backgrounds were significantly less likely to take part and, in contrast to CRC screening using the home-based guaiac faecal occult blood test (gFOBt), women were significantly less likely to attend BSS than men (42\% vs. $45 \%$ ) [7]. For women, this highlights an almost twofold gap between participation in BSS and both breast and cervical screening $[8,9]$.

A recent qualitative study conducted with BSS invitees identified a number of practical and psychological barriers to attendance, and concluded that it was not the presence of concerns about the test but rather the strength of these concerns that was most important in making the decision to participate [10].

While important and informative, previous research into the barriers and facilitators of screening uptake has commonly considered non-participants as a single group; however, there is evidence to suggest that there are distinct sub-groups of non-participants. For example, in the UK FS trial, those who never returned the pre-trial questionnaire were less likely to remember receiving invitation materials and more likely to report procrastination than those who made an active decision not to participate [11]. Furthermore, a quantitative analysis of data from the UK FS trial demonstrated that non-intenders, non-attenders and attenders all had unique demographic and psychological profiles. Non-attenders were the most difficult group to characterise, with only $50 \%$ correctly classified by discriminant analyses [12]. A more nuanced understanding of nonparticipants is particularly important in trying to better understand to what extent decisions about cancer screening are based on well-informed choices. Previous research has identified distinct types of non-attenders within the context of breast cancer screening, and demonstrated among other socioeconomic and psychological differences that passive non-participants are more likely to come from socioeconomically deprived background than active non-participants $[13,14]$. In a more a recent study, Marlow and colleagues highlighted that within non-participants of cervical screening, a majority had not made an active decision to not participate but rather lacked awareness or the means to translate their intention to attend into action [15].

In the context of the BSS, non-participants can be classified into three major groups: those who never respond to the invitation (non-responders, NRs), those who, following the receipt of the invitation or the reminder letter, choose to initiate contact with the screening centre in order to decline the offer (active decliners, ADs), and those who initially confirm but subsequently fail to attend their appointment (non-attenders, NAs). Understanding differences across these major groups of screening non-participants will help focus future research to address the concerns specific to each group. The aim of this study was to quantify the prevalence and combination of barriers to BSS and investigate the extent to which barriers vary across the different types of non-participants.

\section{Methods}

\section{Sample population}

Between May and October 2015, 28 General Practices located across Surrey, London, Norfolk, Tyne and Wear, and Wolverhampton were recruited to this study. Questionnaires were sent to registered patients within each practice who had received their BSS invitation within the last 2 years. Age was used as a proxy for this eligibility criteria; patients who were aged between 55 ( +2 months) and 57 ( +0 months) years were invited to participate. Individuals noted as not being able to read English were identified within each practice and excluded from the invitation process.

\section{Data collection}

Each eligible individual was assigned a unique study ID number. The name, address and study ID number of each person was then sent to Docmail, an online hybrid mailing company, for the delivery of study packs. Each study pack contained a cover letter from the individual's GP, an 8-page questionnaire booklet, and a freepost return envelope (addressed to University College London, UCL). The cover letter included an introduction to the study and instructions on how to participate, encouraging the return of the questionnaire (completed or not) within 2 weeks to avoid a reminder. Survey respondents were informed that by returning a completed questionnaire they were providing consent for their data to be used in this study.

All 28 practices sent a reminder to those who failed to return their questionnaire after an average of 4 weeks and included a replication of the original study pack. All but one practice sent a second reminder, containing a letter only, to those who had not returned a questionnaire after a further 4 weeks (on average). A unique study ID number was attached to each questionnaire and was used to 
identify those requiring a reminder; questionnaires were anonymous.

\section{Measures}

For this study we focused our analysis on a selection of questions within the questionnaire that were relevant to our current research aim.

\section{Demographic characteristics}

Survey respondents were asked to select their response for gender (Male; Female), living arrangement (Single; Married; Cohabiting/ living with partner; Divorced/ separated; Widowed), ethnicity (White; Other), employment status (Employed full-time; Employed part-time; Unemployed; Full-time homemaker; Retired; Student; Disabled or too ill to work; Self-employed) and self-rated health (Excellent; Good; Fair; Poor). Age (in years) was requested as an open response.

\section{Socioeconomic deprivation}

An additional three demographic questions were asked in order to calculate a proxy measure for socioeconomic deprivation. One point was given to an individual if their household did not have a car or van, if they had no formal qualifications and if they did not own their own home [16, 17]. Scores, therefore, ranged from 0 to 3, with high scores indicating higher levels of social deprivation.

\section{Index of multiple deprivation}

To compare the socioeconomic status of responders and non-responders, practices provided a score on the Index of Multiple Deprivation (IMD) [18] for each patient they had invited. IMD is an area-based measure of deprivation based on income, employment, health and disability, education, skills and training, barriers to housing and services, crime and living environment, and can be identified from a postcode [18]. IMD scores are divided into quintiles, with quintiles 1 to 5 representing the least to the most deprived areas.

\section{Interest in BSS}

Participants who indicated they had received an appointment letter for BSS were asked: "When you received the appointment letter, how interested were you in having the bowel scope screening test?" Response options were: "Very", "Moderately", "Slightly", and "Not at all".

\section{Engagement}

The extent to which survey respondents were engaged with the information booklet sent with the BSS invitation was measured by asking: "How much of the information booklet did you read?". Response options were: "None of it", "Some of it", "Most of it", "All of $i t$ " and "Don't know".

\section{BSS invitation response}

Survey respondents were asked "Did you respond to your appointment letter (i.e. confirm or cancel)?", with the following response options: "Yes, I confirmed my appointment", "Yes, I changed my appointment date or time", "Yes, I cancelled my appointment" and "No, I did not respond". Those who selected "No, I did not respond", were then asked if they had then received a reminder letter and, if so, how they had responded to that (response options were the same as above).

\section{Self-reported BSS participation}

To determine whether survey respondents had attended their BSS appointment and received a BSS test, the following question was asked: "Did you have a bowel scope screening test?". Response options were "Yes" and "No". To allow verification of BSS participation status, survey respondents were also asked at the end of the questionnaire if they wished to give permission for the research team to contact the NHS Bowel Cancer Screening Programme to check their response to the BSS invitation. Those who agreed were then asked to provide their name, date of birth and postcode.

\section{Barriers to BSS}

Survey respondents who stated that they had not participated in BSS were asked to indicate their reasons for non-attendance from a pre-specified list of 15 options. Survey respondents were instructed to select all reasons they deemed relevant to them (see Supplementary data page 3). Space was additionally provided for non-listed barriers to be added in an open text format. These were coded and included in the overall list of barriers for analysis.

\section{Statistical analysis}

Chi-square tests of independence were performed to examine the relationship between defined participation/non-participation groups and socio-demographic variables (Tables 1 and 2). We used Fisher's exact test (two-tailed, FET) for variables that had at least one cell with a frequency of less than 5, i.e. 'deprivation' and 'interest' (Table 2). Chi-square test of independence and Fisher's exact test (two tailed) 
Table 1 Descriptive statistics of the overall study sample (row percentages) ${ }^{a}$

\begin{tabular}{|c|c|c|c|c|c|}
\hline & \multicolumn{2}{|c|}{$\begin{array}{l}\text { Participants } \\
(N=1079)\end{array}$} & \multicolumn{2}{|c|}{$\begin{array}{l}\text { Non-participants } \\
(N=243)\end{array}$} & \multirow[t]{2}{*}{$p$-value } \\
\hline & $N$ & (\%) & $N$ & $(\%)$ & \\
\hline \multicolumn{6}{|l|}{ Age } \\
\hline 55 years & 254 & $(23.54)$ & 53 & $(21.81)$ & \multirow[t]{3}{*}{0.385} \\
\hline 56 years & 667 & $(61.82)$ & 146 & $(60.08)$ & \\
\hline 57 years & 158 & $(14.64)$ & 44 & $(18.11)$ & \\
\hline \multicolumn{6}{|l|}{ Gender } \\
\hline Male & 528 & $(48.93)$ & 103 & $(42.39)$ & \multirow[t]{2}{*}{0.065} \\
\hline Female & 551 & $(51.07)$ & 140 & $(57.61)$ & \\
\hline \multicolumn{6}{|l|}{ Ethnicity } \\
\hline Other & 75 & $(6.97)$ & 27 & $(11.20)$ & \multirow[t]{2}{*}{0.026} \\
\hline White & 1001 & $(93.03)$ & 214 & $(88.80)$ & \\
\hline \multicolumn{6}{|l|}{ Living arrangement } \\
\hline Married or living with partner & 860 & $(79.85)$ & 179 & $(73.97)$ & \multirow[t]{2}{*}{0.043} \\
\hline Single, divorced or widowed & 217 & $(20.15)$ & 63 & $(26.03)$ & \\
\hline \multicolumn{6}{|c|}{ Markers of socioeconomic deprivation } \\
\hline markers & 845 & $(78.97)$ & 170 & $(70.54)$ & \multirow[t]{3}{*}{$<0.001$} \\
\hline 1 marker & 171 & $(15.98)$ & 42 & $(17.43)$ & \\
\hline 2-3 markers & 54 & $(5.05)$ & 29 & $(12.03)$ & \\
\hline \multicolumn{6}{|l|}{ Index of Multiple Deprivation IMD } \\
\hline 1st quintile (least deprived) & 401 & $(37.72)$ & 80 & $(33.76)$ & \multirow[t]{5}{*}{0.239} \\
\hline 2nd quintile & 262 & $(24.65)$ & 53 & $(22.36)$ & \\
\hline 3rd quintile & 177 & $(16.65)$ & 40 & $(16.88)$ & \\
\hline 4rd quintile & 130 & $(12.23)$ & 33 & $(13.92)$ & \\
\hline 5th quintile (most deprived) & 93 & $(8.75)$ & 31 & $(13.08)$ & \\
\hline \multicolumn{6}{|l|}{ Paid employment } \\
\hline No & 172 & $(16.09)$ & 61 & $(25.31)$ & \multirow[t]{2}{*}{0.001} \\
\hline Yes & 897 & $(83.91)$ & 180 & $(74.69)$ & \\
\hline \multicolumn{6}{|l|}{ Self-rated health } \\
\hline Excellent, good & 932 & $(86.46)$ & 179 & $(73.97)$ & \multirow[t]{2}{*}{$<0.001$} \\
\hline Fair, poor & 146 & $(13.54)$ & 63 & $(26.03)$ & \\
\hline \multicolumn{6}{|l|}{ Initial interest in Bowel Scope } \\
\hline Very, moderately & 1022 & $(95.13)$ & 123 & $(51.04)$ & \multirow[t]{2}{*}{$<0.001$} \\
\hline Slightly, not at all & 52 & $(4.87)$ & 118 & $(48.96)$ & \\
\hline \multicolumn{6}{|l|}{ Extend to which book was read } \\
\hline None, some or most & 252 & $(28.00)$ & 78 & $(44.32)$ & \multirow[t]{2}{*}{$<0.001$} \\
\hline All of it & 648 & $(72.00)$ & 98 & (55.68) & \\
\hline
\end{tabular}

Note that missing cases are not reported, so that the column frequencies do not always sum up to the total stated at the top of the table ${ }^{a}$ Only eligible sample (i.e. aged between 55 and 57 years)

*The $p$-values are derived from Chi-square tests of Independence

were also used, where appropriate, to examine the relationship between non-participation groups and single barriers ${ }^{1}$ (Tables 3 and 4 ). Where a test indicated a significant relationship, we conducted further pair-wise comparisons using Bonferroni adjusted alpha levels for the number of potential comparisons per variable (i.e. $0.05 / 3=0.016$ ). We used Stata/IC version 14.1 (StataCorp LP, College Station, TX) to conduct the data analysis and only report significant results. 
Table 2 Predictors of screening participation (complete case analysis for both unadjusted and adjusted models, $N=1036$ )

\begin{tabular}{|c|c|c|c|c|c|}
\hline & \multirow[t]{2}{*}{ (\%) } & \multicolumn{2}{|l|}{ Unadjusted } & \multicolumn{2}{|l|}{ Adjusted } \\
\hline & & Odds ratio & $95 \% \mathrm{Cl}$ & Odds ratio & $95 \% \mathrm{Cl}$ \\
\hline \multicolumn{6}{|l|}{ Age } \\
\hline 55 years & $82.9 \%$ & Ref & & Ref. & \\
\hline 56 years & $84.4 \%$ & 1.121 & $0.760-1.656$ & 1.072 & $0.667-1.721$ \\
\hline 57 years & $82.0 \%$ & 0.941 & $0.555-1.596$ & 0.836 & $0.443-1.577$ \\
\hline \multicolumn{6}{|l|}{ Gender } \\
\hline Male & $86.0 \%$ & Ref & & Ref. & \\
\hline Female & $81.7 \%$ & 0.729 & $0.522-1.019$ & 0.770 & $0.512-1.157$ \\
\hline \multicolumn{6}{|l|}{ Ethnicity } \\
\hline Other & $74.0 \%$ & Ref & & Ref. & \\
\hline White & $84.5 \%$ & 1.910 & $1.115-3.272^{*}$ & 1.065 & $0.524-2.162$ \\
\hline \multicolumn{6}{|l|}{ Living arrangement } \\
\hline Married/living with somebody & $85.0 \%$ & Ref & & Ref. & \\
\hline Single/div./wind. & $78.8 \%$ & 0.657 & $0.450-0.959^{*}$ & 0.752 & $0.463-1.222$ \\
\hline \multicolumn{6}{|l|}{ Index of Multiple Deprivation IMD } \\
\hline 1st quintile & $85.2 \%$ & Ref & & Ref. & \\
\hline 2nd quintile & $85.0 \%$ & 0.980 & $0.629-1.526$ & 1.005 & $0.593-1.700$ \\
\hline 3rd quintile & $84.0 \%$ & 0.911 & $0.554-1.497$ & 0.935 & $0.513-1.706$ \\
\hline 4rd quintile & $80.0 \%$ & 0.693 & $0.412-1.164$ & 0.807 & $0.419-1.555$ \\
\hline 5th quintile & $78.4 \%$ & 0.627 & $0.359-1.095$ & 1.082 & $0.518-2.259$ \\
\hline \multicolumn{6}{|c|}{ Markers of socioeconomic deprivation } \\
\hline 0 markers & $85.1 \%$ & Ref & & Ref. & \\
\hline 1 marker & $83.0 \%$ & 0.858 & $0.547-1.346$ & 1.416 & $0.796-2.517$ \\
\hline 2-3 markers & $67.2 \%$ & 0.359 & $0.204-0.635^{* *}$ & 0.807 & $0.371-1.755$ \\
\hline \multicolumn{6}{|l|}{ Paid employment } \\
\hline No & $76.5 \%$ & Ref & & Ref. & \\
\hline Yes & $85.3 \%$ & 1.785 & $1.211-2.629^{* *}$ & 1.407 & $0.856-2.311$ \\
\hline \multicolumn{6}{|l|}{ Self-reported health } \\
\hline Excellent/good & $69.8 \%$ & Ref & & Ref. & \\
\hline Fair/poor & $86.3 \%$ & 2.728 & $1.853-4.016^{* *}$ & 2.306 & $1.410-3.770^{* *}$ \\
\hline \multicolumn{6}{|l|}{ Initial interest in Bowel Scope } \\
\hline Very/moderately & $30.3 \%$ & Ref & & Ref. & \\
\hline Slightly/not at all & $90.8 \%$ & 22.727 & $14.542-35.519^{* *}$ & 22.292 & $13.768-36.094^{* *}$ \\
\hline \multicolumn{6}{|l|}{ Extend to which booklet was read } \\
\hline None/some of it & $76.5 \%$ & & & & \\
\hline All of it & $86.8 \%$ & 2.027 & $1.445-2.842^{* *}$ & 1.136 & $0.737-1.751$ \\
\hline N & & 1036 & & 1036 & \\
\hline
\end{tabular}

\section{Results}

\section{Questionnaire response rate}

The study questionnaire was sent to 3226 eligible individuals with 1478 (45.8\%) completed questionnaires returned. A further 292 (9.1\%) were returned blank. Using study ID numbers and data available in GP records, selected comparisons, i.e. gender and area level deprivation (using postcodes converted to Index of Multiple Deprivation scores), could be made between those who returned a completed questionnaire, those who returned a blank questionnaire (indicating they did not want to respond to the survey) and those who did 
Table 3 Descriptive statistics of the three non-participant groups (column percentages) ${ }^{a}$

\begin{tabular}{|c|c|c|c|c|c|c|c|}
\hline & \multicolumn{2}{|c|}{$\begin{array}{l}\text { NRs } \\
(N=110)\end{array}$} & \multicolumn{2}{|c|}{$\begin{array}{l}\text { ADs } \\
(N=99)\end{array}$} & \multicolumn{2}{|c|}{$\begin{array}{l}\text { NAs } \\
(N=34)\end{array}$} & \multirow[t]{2}{*}{$p$-value } \\
\hline & $N$ & $(\%)$ & $N$ & (\%) & $N$ & $(\%)$ & \\
\hline \multicolumn{8}{|l|}{ Age } \\
\hline 55 years & 28 & $(25.45)$ & 19 & (19.19) & 6 & $(17.65)$ & \multirow[t]{3}{*}{0.666} \\
\hline 56 years & 61 & $(55.45)$ & 64 & $(64.65)$ & 21 & $(61.76)$ & \\
\hline 57 years & 21 & $(19.10)$ & 16 & (16.16) & 7 & $(20.59)$ & \\
\hline \multicolumn{8}{|l|}{ Gender } \\
\hline Male & 57 & $(51.82)$ & 34 & (34.34) & 12 & $(35.29)$ & \multirow[t]{2}{*}{0.026} \\
\hline Female & 53 & $(48.18)$ & 65 & $(65.66)$ & 22 & $(64.71)$ & \\
\hline \multicolumn{8}{|l|}{ Ethnicity } \\
\hline Other & 10 & $(9.17)$ & 11 & $(11.22)$ & 6 & $(17.65)$ & \multirow[t]{2}{*}{0.393} \\
\hline White & 99 & $(90.83)$ & 87 & $(88.78)$ & 28 & $(82.35)$ & \\
\hline \multicolumn{8}{|l|}{ Living arrangement } \\
\hline Married or living with partner & 76 & $(69.72)$ & 78 & (78.79) & 25 & (73.53) & \multirow[t]{2}{*}{0.330} \\
\hline Single, divorced or widowed & 33 & $(30.28)$ & 21 & $(21.21)$ & 9 & $(26.47)$ & \\
\hline \multicolumn{8}{|c|}{ Markers of socioeconomic deprivation } \\
\hline 0 markers & 62 & $(56.88)$ & 82 & $(83.67)$ & 26 & $(76.47)$ & \multirow[t]{3}{*}{$0.001^{a}$} \\
\hline 1 marker & 26 & $(23.85)$ & 11 & $(11.22)$ & 5 & $(14.71)$ & \\
\hline 2-3 markers & 21 & $(19.27)$ & 5 & $(5.10)$ & 3 & $(8.82)$ & \\
\hline \multicolumn{8}{|l|}{ Paid employment } \\
\hline No & 26 & $(23.85)$ & 22 & $(22.45)$ & 13 & $(38.24)$ & \multirow[t]{2}{*}{0.169} \\
\hline Yes & 83 & $(76.15)$ & 76 & $(77.55)$ & 21 & $(61.76)$ & \\
\hline \multicolumn{8}{|l|}{ Self-rated health } \\
\hline Excellent, good & 81 & $(74.31)$ & 71 & $(71.72)$ & 27 & $(79.41)$ & \multirow[t]{2}{*}{0.674} \\
\hline Fair, poor & 28 & $(25.69)$ & 28 & $(28.28)$ & 7 & $(20.59)$ & \\
\hline \multicolumn{8}{|l|}{ Initial interest in Bowel Scope } \\
\hline Very, moderately & 39 & (35.78) & 53 & $(53.54)$ & 31 & $(93.94)$ & \multirow[t]{2}{*}{$<0.001^{a}$} \\
\hline Slightly, not at all & 70 & $(64.22)$ & 46 & $(46.46)$ & 2 & $(6.06)$ & \\
\hline \multicolumn{8}{|l|}{ Extent to which book was read } \\
\hline None, some or most & 45 & $(59.21)$ & 28 & $(35.90)$ & 5 & $(22.73)$ & \multirow[t]{2}{*}{0.001} \\
\hline All of it & 31 & $(40.79)$ & 50 & $(64.10)$ & 17 & $(77.27)$ & \\
\hline
\end{tabular}

NRs Non Responders, ADs Active Decliners, NAs Non-Attenders

${ }^{a}$ Only eligible sample who did not attend the screening (i.e. aged between 55 and 57 years)

"The $p$-values are derived from Chi-square tests of Independence, except for 'markers of socioeconomic deprivation' and 'initial interest in bowel scope' which were both assessed with Fisher's exact test ${ }^{\mathrm{a}}$

Table 4 Number of reasons for not participating stated by nonattenders

\begin{tabular}{|c|c|c|c|c|c|c|c|c|c|}
\hline & \multicolumn{2}{|c|}{$\begin{array}{l}\text { Total } \\
(N=243)\end{array}$} & \multicolumn{2}{|c|}{$\begin{array}{l}\text { NRs } \\
(N=110)\end{array}$} & \multicolumn{2}{|c|}{$\begin{array}{l}\text { ADs } \\
(N=99)\end{array}$} & \multicolumn{2}{|c|}{$\begin{array}{l}\text { NAs } \\
(N=34)\end{array}$} & \multirow[t]{2}{*}{$p$-value } \\
\hline & $\bar{N}$ & (\%) & $\bar{N}$ & (\%) & $N$ & (\%) & $N$ & (\%) & \\
\hline None & 34 & (13.99) & 8 & $(7.27)$ & 22 & $(22.22)$ & 4 & $(11.76)$ & 0.002 \\
\hline One & 89 & (36.63) & 36 & (32.73) & 34 & (34.34) & 19 & (55.88) & \\
\hline $\begin{array}{l}\text { Two or } \\
\text { more }\end{array}$ & 120 & (49.38) & 66 & $(60.00)$ & 43 & $(43.43)$ & 11 & (32.35) & \\
\hline
\end{tabular}

NRs Non Responders, ADs Active Decliners, NAs Non-Attenders *The $p$-value is derived from Fisher's exact test not respond at all. Women were found to be significantly more likely to answer the questionnaire than men $(48.1 \%$ vs $\left.43.5 \%, x^{2}(1, N=3226)=6.78, p=0.009\right)$. Furthermore, responders to the questionnaire were more likely to live in a less deprived area $\left(x^{2}(4, N=2915)=13.30, p<0.001\right)$.

Among those who returned a completed questionnaire, $38(2.6 \%)$ were removed from the analysis due to stated age being older or younger than expected for the study sample. Of the questionnaire respondents included in the final analysis $(n=1440)$, the 


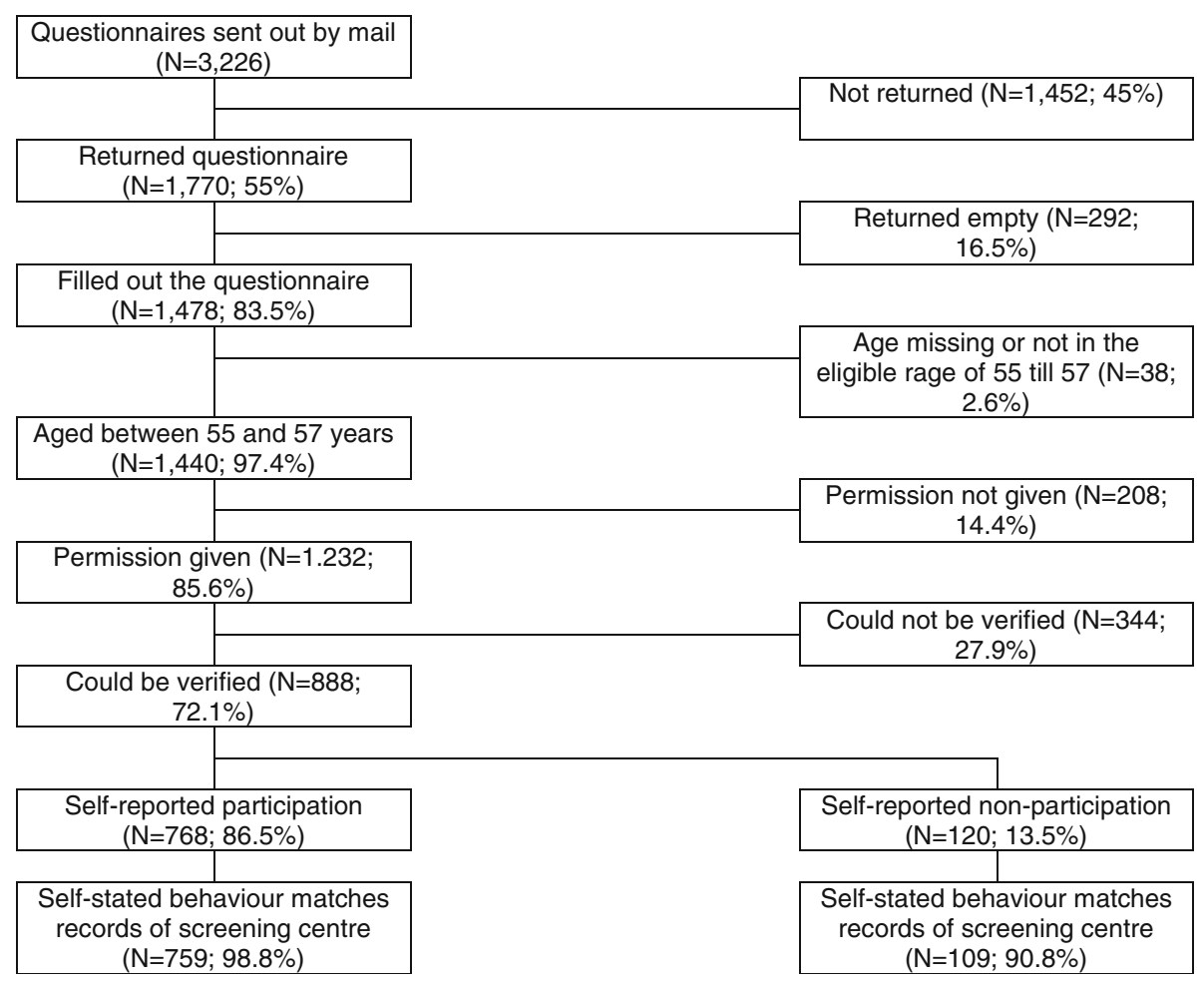

Fig. 1 The flow of participants through the study

majority were female (52.9\%), married or cohabiting (78.2\%), white $(91.6 \%)$, and living in areas with the lowest levels of deprivation (38.8\%). Figure 1 shows the flow of survey respondents through the study.

\section{BSS attendance}

\section{Variation in socio-demographic variables by BSS} attendance status

Table 1 presents a summary of demographic variables by participation. Due to small sample size, response options were combined for some variables. Among those who returned a completed questionnaire, 1079 $(81.62 \%)$ confirmed and attended their BSS appointment, and $243(18.38 \%)$ did not. Among those who gave us permission, there was $90.8 \%$ correspondence between self-reported and verified participation status.

BSS non-participants were more likely to be from ethnically diverse backgrounds $\left(x^{2}(2, N=1317)=4.94\right.$, $p=0.026)$, not living with a partner $\left(x^{2}(2, N=1319)=\right.$ 4.09, $p=0.043)$, more deprived $\left(x^{2}(2, N=1311)=8.00\right.$, $p=0.005)$, and in paid employment $\left(\mathrm{x}^{2}(2, N=1310)=\right.$ $11.44, p=0.001)$. Similarly, those who did not participate in BSS were more likely to report a poor health status $\left(x^{2}(2, N=1320)=23.13, p<0.001\right)$, and low initial interest in having the BSS test $\left(x^{2}(2, N=1315)=\right.$ 340.39, $p<0.001)$. Relatedly, BSS non-participants were also less likely to have read the whole information booklet $\left(x^{2}(2, N=1076)=18.44, p<0.001\right)$. A multivariable regression (see Table 2) demonstrated that only self-reported health and initial interest in bowel scope remained significant predictors of BSS attendance.

\section{Variation in socio-demographic variables by non- participant subgroups}

Of the 243 BSS non-participants, 110 did not respond to their BSS invitation (NRs; 45.3\%), 99 actively declined their BSS invitation (ADs; 40.7\%) and 34 confirmed their BSS appointment but subsequently failed to attend (NAs; 14.0\%). Table 3 displays the sociodemographic variables for the three different types of non-participation. Chi-square tests of independence showed that the three types of non-participation differed in their gender composition and engagement with the information booklet $(p<0.05)$. Fisher's exact test showed that initial interest in screening and socioeconomic deprivation also significantly varied across the three groups $(p<0.05, \mathrm{FET})$.

Pairwise comparisons, using a Bonferroni corrected significance level $(p<0.016)$, revealed that compared to ADs, NRs were more likely to be male $\left(x^{2}\right.$ (2, $N$ $=209)=6.47, p=0.011)$ and be more deprived $(p<$ 0.001 , FET). NRs were less likely to have read the 
whole booklet than ADs $\left(x^{2}(2, N=154)=8.39, p=\right.$ $0.004)$ or NAs $\left(x^{2}(2, N=98)=9.09, p=0.003\right)$. Similarly, NRs stated significantly lower initial interest in having the BSS test than either ADs $\left(x^{2}(2, N=208)=\right.$ $6.63, p=0.010)$ or NAs $(p<0.001$, FET $)$. While there was no difference between ADs and NAs with regard to their level of engagement, ADs indicated significantly lower levels of initial interest in BSS $(p<0.001$, FET).

\section{Barriers}

\section{Number of barriers}

209 (86\%) BSS non-participants gave at least one reason for not participating in BSS: NRs = 102 (93\%), ADs $=77$ $(78 \%)$ and NAs $=30(88 \%)$; Table 4 . Those who answered the question gave on average 2.12 reasons (NRs $=2.35$, ADs $=2.03$ and NAs =1.6). The number of reasons endorsed varied by the type of non-participant ( $p$ $=0.002$, FET). Pairwise comparisons show that NRs were more likely to state two or more reasons for not participating than ADs $\left(x^{2}(2, N=209)=10.89, p=\right.$ $0.004)$ and NAs $(p=0.014$, FET $)$. There was no difference between ADs and NAs $(p=0.084, \mathrm{FET})$.

\section{Barriers by subgroup}

Table 5 shows the list of barriers and the proportion of the three non-participant groups endorsing them (the two items on the enema were combined). Worrying the test would be painful (33.01\%), embarrassing
(30.14\%) and simply not personally needed (25.84\%) were the three most commonly endorsed barriers overall. One interesting result was that NAs had a lower rate of "not needed" and a higher rate of "other test done", While these two items could have been referring to a related issue. However, Appendices 1 and 2 show that none of our respondents ever endorsed both items together.

\section{Combination of barriers}

Pain and embarrassment was the most frequent combination of barriers to BSS (33.33\%), followed by embarrassment and the enema (23.33\%), and thirdly the combination of pain and worry about harm to the bowel (20.00\%); (see Appendices 1 and 2 for details).

\section{Discussion}

This study aimed to identify the demographic profile of BSS participants and non-participants, and importantly to compare profiles and reasons for BSS non-participation across three distinct subgroups of non-participants: those who do not respond to the screening invitation (NRs), those who actively decline the invitation (ADs) and those who confirm their appointment but then do not attend (NAs).

This is the largest study of self-reported participation in BSS to date, and the first to consider sub-groups of non-participants. In our study, as expected, the majority of questionnaire respondents had participated in

Table 5 Stated reasons for not participating across the three non-participant groups $(N=209)$

\begin{tabular}{|c|c|c|c|c|c|c|c|c|c|}
\hline & \multicolumn{2}{|c|}{$\begin{array}{l}\text { Total } \\
(N=209)\end{array}$} & \multicolumn{2}{|c|}{$\begin{array}{l}\text { NRs } \\
(N=102)\end{array}$} & \multicolumn{2}{|c|}{$\begin{array}{l}\text { ADs } \\
(N=77)\end{array}$} & \multicolumn{2}{|c|}{$\begin{array}{l}\text { NAs } \\
(N=30)\end{array}$} & \multirow[t]{2}{*}{$p$-value } \\
\hline & $N$ & $\%$ & $N$ & $\%$ & $N$ & $\%$ & $N$ & $\%$ & \\
\hline Worried about pain & 69 & (33.01) & 38 & $(37.25)$ & 25 & $(32.47)$ & 6 & $(20.00)$ & $0.208^{b}$ \\
\hline Embarrassing & 63 & $(30.14)$ & 39 & $(38.24)$ & 22 & $(28.57)$ & 2 & $(6.67)$ & 0.002 \\
\hline Not needed & 54 & $(25.84)$ & 31 & (30.39) & 22 & $(28.57)$ & 1 & (3.33) & 0.004 \\
\hline Worried about harm & 53 & $(25.36)$ & 23 & $(22.55)$ & 25 & $(32.47)$ & 5 & $(16.67)$ & $0.159^{b}$ \\
\hline Appointment problems & 51 & $(24.40)$ & 24 & (23.53) & 19 & $(24.68)$ & 8 & $(26.67)$ & $0.938^{b}$ \\
\hline Enema not wanted & 44 & $(21.05)$ & 24 & $(23.53)$ & 14 & (18.18) & 6 & $(20.00)$ & $0.678^{b}$ \\
\hline No time & 34 & $(16.27)$ & 20 & $(19.61)$ & 10 & (12.99) & 4 & (13.33) & 0.469 \\
\hline Worried about result & 16 & $(7.66)$ & 15 & $(14.71)$ & 0 & $(0.00)$ & 1 & (3.33) & $<0.001$ \\
\hline Medical reasons & 16 & $(7.66)$ & 4 & $(3.92)$ & 5 & $(6.49)$ & 7 & $(23.33)$ & 0.005 \\
\hline Unacceptable & 12 & $(5.74)$ & 7 & $(6.86)$ & 5 & $(6.49)$ & 0 & $(0.00)$ & 0.428 \\
\hline Bad experience & 11 & $(5.26)$ & 6 & $(5.88)$ & 3 & $(3.90)$ & 2 & $(6.67)$ & 0.760 \\
\hline Other test done $\mathrm{a}^{\mathrm{a}}$ & 11 & $(5.26)$ & 2 & $(1.96)$ & 5 & $(6.49)$ & 4 & (13.33) & 0.030 \\
\hline Forgot & 7 & (3.35) & 6 & $(5.88)$ & 0 & $(0.00)$ & 1 & (3.33) & 0.070 \\
\hline Financial $^{a}$ problems & 3 & $(1.44)$ & 1 & $(0.98)$ & 1 & $(1.30)$ & 1 & (3.33) & 0.537 \\
\hline
\end{tabular}

NRs Non Responders, ADs Active Decliners, NAs Non-Attenders

The provided options 'Not understanding the information booklet' and 'transport problems' were not selected by anyone in either of the three groups ${ }^{a}$ Emerged from free text section

*The $p$-values are derived from Fisher's exact test if not otherwise stated $\left({ }^{b} \mathrm{Chi}\right.$-square test of Independence) 
BSS. However, within the non-participant group, variation allowed sub-group comparisons to be made; the majority were NRs, followed by ADs and then NAs. Compared to BSS participants, non-participants as a whole were more likely to be female, not married or living in a relationship, in paid employment, and from more socio-economically deprived backgrounds. These results closely match those described in a recent analysis of participation in the first 14 months of BSS roll-out [7]. Additionally, non-participants were less likely to state that they were interested in having the test when they first received the invitation and to have read the information leaflet that was sent as part of the invitation. This highlights a need to find other ways to engage invitees with the BSS opportunity.

We found important differences between the three sub-groups in their demographic profile and reported barriers to BSS participation. Specifically, NAs noted fewer barriers, and were more likely to report higher initial interest in having the BSS test, than the other two groups. The most frequently barriers reported by NAs focused on more practical elements of attendance (e.g. appointment problems and medical reasons), suggesting that this sub-group of non-participants may have had higher intentions to have the BSS test but that practical reasons prevented them from actually attending their appointment. This supports recent observations in non-attenders for diagnostic colonoscopy in the NHS Bowel Cancer Screening Programme [19]. In comparison, NRs and ADs were more likely to endorse anticipated pain and embarrassment as reasons for not participating in BSS, which suggests that these emotional barriers may have influenced the low initial interest in having the BSS test among these two sub-groups of non-participants.

Several of the barriers reported in this study have also been described in previous qualitative studies. The perceived lack of need has also been identified by Hall and colleagues [10], as part of their interview study of screeners and non-screeners; while, McCaffery and colleagues [11] also reported that perceived lack of susceptibility and lack of symptoms were important factors in the decision to decline screening. However, unlike the findings by McCaffery and colleagues [11] that suggested procedural barriers, such as anticipated embarrassment and pain and discomfort, to be reported as minor factors in the decision to decline, our study found these barriers to be much more prominent than previously reported.

The findings by Hall and colleagues [10] suggest that both BSS participants and non-participants anticipated the screening procedure to be unpleasant and invasive, and this often led to strong emotional responses to the invitation materials. In our study, perceiving the procedure to not be important but time consuming and embarrassing was prominent among those who did not read all the information materials. It is possible that with increasing awareness of the existing Bowel Cancer Screening Programme using gFOBt, and knowing that this test offers a much less invasive alternative at the age of 60, people might be more likely to question the invasive nature of BSS. Uptake of BSS might benefit from a better distinction between the two aspects of the programme, with bowel scope aiming to prevent CRC and the current gFOBt test being squarely aimed at detecting CRC early.

Distinguishing between different groups of BSS non-participants enables screening programme managers, practitioners, and policy makers to identify different barriers for different subgroups and develop more targeted interventions. Such interventions could include the use of narratives from previous participants, or reference to data showing that a vast majority of people who had the test report positive experiences. Similarly, previous research has identified that offering same-sex practitioners is a popular option, particularly among women who previously did not respond to the test invitation, and may be an important factor in helping to reduce anticipated embarrassment $[20,21]$. A more proactive approach to informing invitees about the intensity of pain and discomfort to expect, and of ways these can be reduced, would also be important. For example, enabling screening invitees to choose early on whether they prefer pain relief in the form of Entonox, and when it is given (either in response to discomfort or pre-emptively to avoid pain and discomfort) could be considered.

Finally, while NAs represent a small proportion of BSS non-participants, they should not be forgotten. The programme has the strongest mandate to try and help these individuals realize their intention to have the test. For NAs, the main barriers were practical and medical aspects and so, for this group specifically, more autonomy over the appointment booking system and reminders of the self-referral process may be particularly important.

This study had a number of limitations. The study was carried out in primary care which enabled us identify eligible respondents without having to interfere with the invitation process. However, it should be acknowledged that we were limited to selecting among practices who were located in areas in which BSS had been rolled out. Despite our best efforts not all practices were available to participate so our selection of 28 practices did not constitute a probabilistic sample which may have introduced bias. 
The survey had a response rate of only $45.8 \%$, which is good compared with many similar CRC screening surveys, but survey respondents were more likely to come from affluent areas and be female which may well have caused uptake in this study to be significantly higher compared with what has been reported in the programme [7]. Overall, it is important to acknowledge that compared with the general population our sample was also more affluent and educated. In addition, as we were unable to provide translated versions of our questionnaires, our ability to identify barriers specific to different ethnic groups was limited.

Although our study analysed barriers of screening based on self-reported uptake, the results remain relevant as the self-reported screening behaviours proved to be very accurate. In our questionnaire, we asked responders to state whether they would allow the research team to check their screening status in their health records. While a total of 1232 responders gave permission to look up their participation records, only 888 could correctly be identified. This discrepancy may have been the result of unclear handwriting, as responders had to provide their name, date of birth and postcode by hand. Comparing the self-reported uptake of identified responders with participation recorded by the programme, shows accurate self-reported participation in $98.8 \%(N=$ $759)$ of responders. Similarly, 90.9\% $(N=109)$ of those who declared that they did not participate had matching records. The lower accuracy for BSS non-participants is likely caused by them taking part after completing the questionnaire. Objective uptake data were obtained after study participants gave their permission and sent back the questionnaire to the research team. Relatedly, as a result of the relatively small proportion of BSS non-attenders, this study was not powered to properly test the significance levels of the comparison across barriers by SES or by non-participant subgroups.

A further limitation is that the study did not assess the delay between having received the BSS invitation and answering the questionnaire. Although the analysis was restricted to responders who indicated that their age was between 55 and 57 years at the time of the questionnaire, the length of time period between receiving BSS invitation and the questionnaire could have influenced the naming of the participation barriers.

Our study has strongly implicated pain and embarrassment of the test as common barriers. While this finding is a useful starting point, there would be value in further refining exactly what aspects of the test are perceived as painful and embarrassing, in order to develop potential strategies to make the test more acceptable. Furthermore, the fact that the combination of both terms was frequently mentioned, indicates that there might be some considerable overlap. Understanding the mechanisms behind this relationship might also lead to better decisions about how to intervene.

Most importantly, future research needs to identify how to balance the tension between not wanting to put people off and presenting enough information about the test to reassure those with strong negative preconceptions. In addition to written information, this may well include more facile, flexible and personal approaches, such as targeted messages, and patient navigation. Future research could also identify enabling factors by asking participants more directly what helped them overcome some of the barriers that were endorsed by them.

Not needing the test was another frequently mentioned barrier by NRs and ADs. Future research needs to identify the motivation behind citing this barrier, but it is likely that there is a lack of understanding of the unprecedented public health benefit associated with FS, particularly its ability to prevent CRC. The UK FS Trial went some way to develop pictorial information about the adenoma-cancer sequence, which was found to significantly increase knowledge and motivation [22]. Unfortunately, this approach has not been adopted in the education provided with the current information leaflet.

\section{Conclusions}

This study highlighted that there are important variations between different types of non-participants in the bowel scope screening branch of the BCSP. Pain and embarrassment seem to be important concerns among those who either never respond or actively decline the offer. By contrast, people who initially confirm their invitation for bowel scope screening but do not attend their appointment are more interested and informed, and tend to come against more specific issues relating to acting on their intention. Interventions to improve uptake among these different types of non-participants should be more nuanced and use targeted strategies to improve uptake. In the short term, this should involve placing greater emphasis on the perceived benefits of the test as part of the initial invitation, using additional reminders for the test and the ability to self-refer, and more flexible appointment booking systems to reduce the number of NA's.

\section{Endnotes}

${ }^{1}$ Due to low numbers we did not stratify combination of barriers by sub-group. 


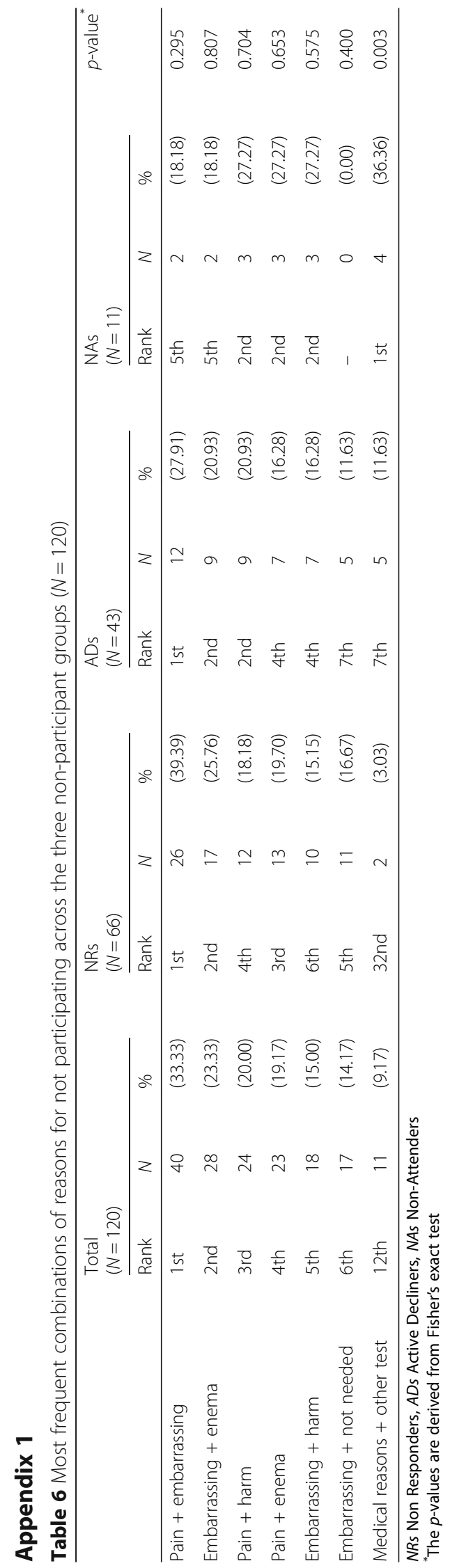




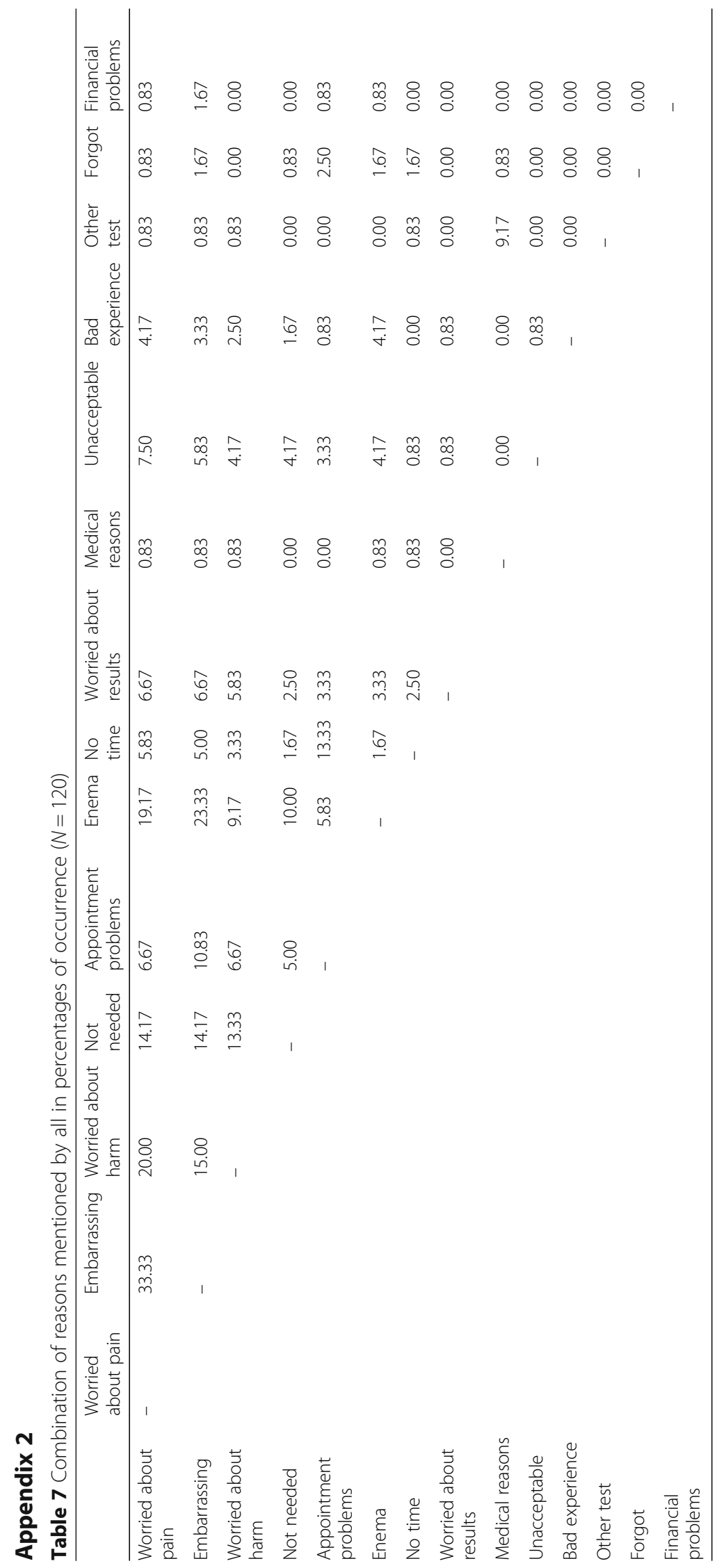




\section{Abbreviations}

AD: Active Decliner; BSS: Bowel Scope Screening; CRC: Colorectal cancer; FET: Fischer's Exact Test; FS: Flexible Sigmoidoscopy; IMD: Index of Multiple Deprivation; NA: Non-attender; NR: Non-responder; UCL: University College London

\section{Acknowledgements}

We would like to thank all participating General Practices, and members of the Bowel Cancer Screening Programme who helped with identification of participants and verification of BSS participation status.

\section{Funding}

This study was funded by a project grant from Cancer Research UK (C27064) A17326) to CW. The funder had no influence on the design of the study, data collection, analysis, interpretation or any part of manuscript development, review or submission.

\section{Availability of data and materials}

The datasets generated and/or analysed during the current study are not publicly available due to data confidentiality but are available from the corresponding author on reasonable request.

\section{Authors' contributions}

CWW conceived the study plans, design, supervised questionnaire development, data collection analysis and led the write up. BB and LMG led the questionnare development, recruitment of GPs and data collection. RK and HS led collection of follow up data screening data. SS led data analysis and write up of the results. All authors contributed and approved the manuscript.

\section{Ethics approval and consent to participate}

This study including our consent procedure (see below) received ethical approval from NRES Committee South Central-Berkshire B (letter dated 21st May 2014). Survey respondents were informed that by returning a completed questionnaire they were providing consent for their data to be used in this study.

\section{Consent for publication}

NA

\section{Competing interests}

The authors declare that they have no competing interests.

\section{Publisher's Note}

Springer Nature remains neutral with regard to jurisdictional claims in published maps and institutional affiliations.

\section{Author details}

${ }^{1}$ Research Department of Behavioural Science and Health, University College London, Gower Street, London WC1E 6BT, UK. ${ }^{2} \mathrm{MRC} / \mathrm{CSO}$ Social and Public Health Sciences Unit, University of Glasgow, Glasgow G2 3QB, UK. ${ }^{3}$ School of Health Sciences, University of Surrey, Guildford GU2 7XH, UK.

Received: 1 May 2018 Accepted: 25 September 2018

Published online: 05 October 2018

\section{References}

1. Cancer Research UK. Bowel Cancer Statistics. 2014. http://www. cancerresearchuk.org/health-professional/cancer-statistics/statistics-bycancer-type/bowel-cancer\#heading-One. Accessed 10 Feb 2018

2. Atkin W, Edwards R, Kralj-Hans I, Wooldrage K, Hart AR, Northover JM, Parkin DM, Wardle J, Duffy SW, Cuzick J, UK Flexible Sigmoidoscopy Trial Investigators. Once-only flexible sigmoidoscopy screening in prevention of colorectal cancer: a multicentre randomised controlled trial. Lancet. 2010;375(9726):1624-33. https://doi.org/10.1016/S01406736(10)60551-X.

3. Segnan N, Armaroli P, Bonelli L, Risio M, Sciallero S, Zappa M, Andreoni B, Arrigoni A, Bisanti L, Casella C, Crosta C, Falcini F, Ferrero F, Giacomin A, Giuliani O, Santarelli A, Visioli CB, Zanetti R, Atkin WS, Senore C, SCORE Working Group. Once-only sigmoidoscopy in colorectal cancer screening: follow-up findings of the Italian randomized controlled trial-SCORE. J Natl Cancer. 2011;103(17):1310-22. https://doi.org/10.1093/jnci/djr284

4. Schoen RE, Pinsky PF, Weissfeld JL, Yokochi LA, Church T, Laiyemo AO, Bresalier R, Andriole GL, Buys SS, Crawford ED, Fouad MN, Isaacs C, Johnson CC, Reding DJ, O'Brien B, Carrick DM, Wright P, Riley TL, Purdue MP, Izmirlian G, Kramer BS, Miller AB, Gohagan JK, Prorok PC, Berg CD, PLCO Project Team. Colorectal-cancer incidence and mortality with screening flexible sigmoidoscopy. New Engl J Med. 2012;366:2345-57. https://doi.org/10.1056/NEJMoa1114635.

5. Atkin W, Wooldrage K, Parkin DM, Kralj-Hans I, MacRae E, Shah U. Long term effects of once-only flexible sigmoidoscopy screening after 17 years of follow-up: the UK flexible sigmoidoscopy screening randomised controlled trial. Lancet. 2017;389(10076):1299-311. https://doi.org/10.1016/S01406736(17)30396-3.

6. Geurts SME, Massat NJ, Duffy SW. Likely effect of adding flexible sigmoidoscopy to the English NHS bowel Cancer screening Programme: impact on colorectal cancer cases and deaths. Br J Cancer. 2015;113(1): 142-9. https://doi.org/10.1038/bjc.2015.76.

7. McGregor LM, Bonello B, Kerrison RS, Nickerson C, Baio G, Berkman L, Rees CJ, Atkin W, Wardle J, von Wagner C. Uptake of bowel scope (flexible sigmoidoscopy) screening in the English National Programme: an analysis of the first fourteen months. J Med Screen. 2016;23(2):77-82. https://doi.org/ $10.1177 / 0969141315604659$.

8. NHS Digital. Cervical Screening Programme, England - 2015-2016. 2016a. http:// content.digital.nhs.uk/searchcatalogue?productid=23523\&q=title\%3a\%22Cervical +screening+programme\%22\&sort=Relevance\&size=10\&page=1\#top. Accessed 10 Feb 2018.

9. NHS Digital. Breast Screening Programme, England - 2015-2016. 2016b. http://content.digital.nhs.uk/searchcatalogue?productid=24457\&q= title\%3a\%22Breast+Screening+Programme\%2c+England\%22\&sort= Relevance\&size=10\&page=1\#top. Accessed 10 Feb 2018.

10. Hall N, Birt L, Rees CJ, Walter FM, Elliot E, Ritchie M, Weller D, Rubin G. Concerns, perceived need and compete priorities: a qualitative exploration of decision-making and non-participation in a populationbased flexible sigmoidoscopy screening programme to prevent colorectal cancer. BMJ Open. 2016;6(11):e012304. https://doi.org/10.1136/ bmjopen-2016-012304.

11. McCaffery K, Borril J, Williamson S, Taylor T, Sutton S, Atkin W, Wardle J. Declining the offer of flexible sigmoidoscopy screening for bowel cancer: a qualitative investigation of the decision-making process. Soc Sci Med. 2001:53:679-91. https://doi.org/10.1016/S0277-9536(00)00375-0.

12. Power E, Van Jaarsveld CH, McCaffery K, Miles A, Atkin W, Wardle J. Understanding intentions and action in colorectal cancer screening. Ann Behav Med. 2008;35:285. https://doi.org/10.1007/s12160-008-9034-y.

13. Aro AR, de Koning HJ, Absetz P, Schreck M. Two distinct groups of nonattenders in an organized mammography screening program. Breast Cancer Res Treat. 2001;70(2):145-53.

14. Jensen LF, Fischer Pedersen A, Andersen B, Vedsted P. Identifying specific non-attending groups in breast cancer screening - population-based registry study of participation and socio-demography. BMC Cancer. 2012;12: 518. https://doi.org/10.1186/1471-2407-12-518.

15. Marlow L, Chorley A, Haddrell J, Ferrer R, Waller J. Understanding the heterogeneity of cervical cancer screening non-participants: data from a national sample of British women. Eur J Cancer. 2017;80:30-8. https://doi. org/10.1016/j.ejca.2017.04.017.

16. Wardle J, McCaffery K, Nadel M, Atkin W. Socioeconomic differences in cancer screening participation: comparing cognitive and psychological explanations. Soc Sci Med. 2004;59(2):249-61.

17. McGregor LM, von Wagner C, Vart G, Yuen WC, Raine R, Wardle J, Robb KA. The impact of supplementary narrative-based information on colorectal cancer screening beliefs and intention. BMC Cancer. 2015;15:162. https://doi. org/10.1186/s12885-015-1167-3.

18. Department for Communities and Local Government. The English Indices of Deprivation 2010. 2011. https://www.gov.uk/government/uploads/system/ uploads/attachment_data/file/6871/1871208.pdf. Accessed 10 Feb 2018.

19. Plumb AA, Ghanouni A, Rainbow S, Djedovic N, Marshall S, Stein J, Taylor SA, Halligan S, Lyratzopulos Y, von Wagner C. Patient factors associated with nonattendance at colonoscopy after a positive screening faecal occult blood test. J Med Screen. 2017;24:12-9. https://doi.org/10.1177/096914316645629.

20. Kerrison RS, McGregor LM, Marshall S, Isitt J, Counsell N, Rees CJ, von Wagner C. Improving uptake of flexible sigmoidoscopy screening: a 
randomized trial of nonparticipant reminders in the English screening Programme. Endoscopy. 2017;49(1):35-43. https://doi.org/10.1055/s-0042-118452.

21. Kerrison RS, McGregor LM, Marshall S, Isitt J, Counsell N, Wardle J, von Wagner C. Use of a 12 months' self-referral reminder to facilitate uptake of bowel scope (flexible sigmoidoscopy) screening in previous nonresponders: a London-based feasibility study. Br J Cancer. 2016;114(7):751-8. https://doi.org/10.1038/bjc.2016.43.

22. Brotherstone $\mathrm{H}$, Miles A, Robb KA, Atkin W, Wardle J. The impact of illustrations on public understanding of the aim of cancer screening. Patient Educ Couns. 2006;63(3):328-35. https://doi.org/10.1016/j.pec.2006.03.016.

Ready to submit your research? Choose BMC and benefit from:

- fast, convenient online submission

- thorough peer review by experienced researchers in your field

- rapid publication on acceptance

- support for research data, including large and complex data types

- gold Open Access which fosters wider collaboration and increased citations

- maximum visibility for your research: over $100 \mathrm{M}$ website views per year

At BMC, research is always in progress.

Learn more biomedcentral.com/submissions 